\title{
EL CONCEPTO DE BELLEZA EN LA OBRA DEL HERMANO ROGER DE TAIZÉ
}

\author{
SALVADOR GARCÍA ARNILLAS \\ Universitat Ramon Llull, Barcelona
}

RESUMEN: El artículo expone el concepto de belleza del hermano Roger de Taizé a partir del análisis de sus escritos y plantea su papel fundamental en la vocación de la Comunidad de Taizé, junto con la sencillez y la provisionalidad. A pesar de que el hermano Roger no abordó esta cuestión de modo sistemático, como tampoco lo hizo con la mayoría de los temas que trataba, se pueden establecer tres focos de interés: la contemplación de la belleza sencilla de la creación, la relación entre la belleza y la creación artística, y la capacidad mediadora de la belleza en la oración litúrgica.

PALABRAS CLAVE: belleza; estética; experiencia religiosa; Taizé.

\section{The concept of beauty in the writings of Brother Roger of Taizé}

ABSTRACT: The paper approaches the concept of beauty from Brother Roger's writings and proposes its essential role in the vocation of Taizé Community, together with simplicity and provisional. Even though Brother Roger never treated this topic in a systematic way, as he usually did with others, we can note three focal points: the contemplation of the simple beauty of creation, the relation between beauty and artistic creation, and the mediation capacity of beauty in liturgical prayer.

KEY WORDS: beauty; aesthetics; religious experience; Taizé.

Los estudios que se han realizado sobre la figura del hermano Roger de Taizé (1915-2005), fundador de la Comunidad de Taizé, se han centrado principalmente en aspectos relativos a su biografía, su comprensión del ecumenismo y su espiritualidad, y, cuando se han tratado aspectos estéticos, se limitaban a analizar los llamados "cantos de Taizé»" ${ }^{1}$ Sin embargo, entre las intuiciones espirituales del hermano Roger que determinan la vocación de la Comunidad de Taizé, se encuentra, además de la sencillez y la provisionalidad, la belleza, ya que jugó un papel esencial en la vida del hermano Roger y condicionó las manifestaciones estéticas que encontramos en dicha comunidad, especialmente en lo relativo a la arquitectura, la liturgia, la música y el arte $^{2}$. En sus diarios no se encuentran muchas referencias explícitas a la belleza, pero, aquellos pasajes

1 Entre las numerosas biografías del hermano Roger, destacan las siguientes obras: BRIco, R., Frère Roger et Taizé, París, Les éditions du Cerf, 1982; Chiron, Y., Frère Roger. Le fondateur de Taizé, París, Perrin, 2008; Laplane, S., Frère Roger, de Taizé, París, Les éditions du Cerf, 2015; SpINK, K., Hermano Roger. La vida del fundador de Taizé, Barcelona, Herder, ${ }^{3} 2009$. Asimismo, en las obras que abordan la historia de la Comunidad de Taizé se encuentran numerosos análisis sobre la figura del hermano Roger: Escatiff, J.-C., y Rasiwala, M., Histoire de Taizé, París, Éditions du Seuil, 2008; Paupert, J. M., Taizé et l'église de demain, París, Ed. Fayard, 1967; Restrepo, I., Taizé, Salamanca, Ediciones Sígueme, 1975; Scatena, S., Taizé una parabola di unità, Bolonia, Il Mulino, 2018.

2 Para un análisis global de la belleza en la experiencia religiosa y en las manifestaciones estéticas de la Comunidad de Taizé, cf. García Arnillas, S., La belleza sencilla de Taizé. Arquitectura, liturgia, música y arte, Madrid, BAC, 2018. 
en los que aparece destilan un sentido poético extraordinario que bebe de las profundidades de su vida espiritual. En otros escritos tampoco aborda esta cuestión de modo sistemático, como tampoco lo hace con otros temas teológicos, lo que no significa que no sea relevante. Más bien se trata de un estilo muy personal de escritura en el que prevalece la vivencia íntima, la comprensión espiritual, y no tanto la elaboración exacta de un concepto.

La naturaleza es el ámbito donde el sentido de la belleza más se acentúa en el hermano Roger y en su diario las referencias a la belleza de la creación son las más numerosas. También destaca su sensibilidad hacia la belleza de la oración litúrgica, de manera particular en el canto, y siempre referida a la sencillez. Y, por último, la belleza artística también le interpela, especialmente a través de la música, en particular la obra de Bach. Por el resto de las artes no se aprecia una especial inclinación si bien siempre valoró la creación artística como un don de Dios y huyó de todo puritanismo en el uso del arte por parte de la Iglesia. Pero todos estos ámbitos tienen en común que se trata de una belleza sencilla, de acuerdo, según se ha indicado, con una de las intuiciones espirituales fundamentales del hermano Roger que está recogida en Las fuentes de Taizé, un texto no normativo en el que se expresa lo esencial para la vida comunitaria: «El espíritu de pobreza no consiste en hacer las cosas de manera mísera, sino en disponerlo todo con imaginación en la belleza sencilla de la creación»³.

\section{LA BELLEZA SENCILLA DE LA CREACIÓN}

\subsection{La poesía de la naturaleza}

La sensibilidad del hermano Roger por la belleza de la naturaleza se remonta a su infancia. Cuando evoca su niñez en el pueblo de Provence en entrevistas o en sus propias notas del diario personal, sus recuerdos rezuman felicidad: «[...] mi madre imprimió a la casa un ambiente de fiesta continua. Todo estaba bien adornado, con flores, con jardines, la nieve resplandecía en los campos y llevábamos una vida de gran espontaneidad y alegría. Todo esto ha marcado enormemente mi vida $»^{4}$. La casa familiar estaba situada en un entorno natural excepcional que permitió disfrutar al hermano Roger de la naturaleza desde su más tierna infancia. La delicadeza de su madre, los juegos en el jardín, los paseos familiares por los senderos cercanos contribuyeron a potenciar en él una especial sensibilidad por la naturaleza y la belleza de la creación, que jamás le abandonaría:

3 Roger, F., «Les sources de Taizé» en Roger, F., Les écrits fondateurs, Taizé, Ateliers et Presses de Taizé, 2011, p. 46.

4 Entrevista personal, 26 de diciembre de 1968, recogida en Restrepo, I., Taizé, Salamanca, Sígueme, 1975, p. 24. 
«Cada vez que rememoro un acontecimiento de mi infancia, veo la luz, sé la hora del día en que se produjo, si era por la mañana, al mediodía, al atardecer. Cuando era niño, mi madre me hacía pasar mucho tiempo en el jardín. Pensaba que era bueno para mi salud. Desde entonces, siempre he amado las flores, los árboles. Cuando estaba en Roma con motivo del Concilio, contemplaba los cielos italianos entre los árboles, y esta imagen aún la tengo en mi retina» ${ }^{5}$.

Una de esas emociones infantiles que le llenaban de felicidad era la ilusión que sentía al levantarse el día de su cumpleaños que le hacía bajar corriendo al jardín para ver si las peonías habían abierto sus flores ${ }^{6}$. Estos pequeños recuerdos tan nítidos y alegres nos indican lo estrechamente que vivía el trascurso de su vida con las estaciones naturales, una percepción del tiempo habitual en el mundo rural, pero que no deja de evocar una profunda sensibilidad hacia la naturaleza y su belleza.

Una vez trasladada la familia al pueblo de Oron, a los dieciséis años enferma de una tuberculosis pulmonar que le obliga a estar en reposo durante varios años y que le impide cursar educación secundaria. Durante estos años de convalecencia, la lectura es su principal actividad, así como los largos paseos por el campo y el bosque que llegan a durar dos o tres horas, cuando su estado de salud se lo permite. El contacto estrecho con la naturaleza que experimenta durante sus paseos le hace admirarse por su belleza y experimentar un sentimiento de armonía con ella, y escribir sus reflexiones de regreso a casa.

La extrema sensibilidad que tenía el hermano Roger por la naturaleza se refleja en los abundantes pasajes de sus diarios en los que recoge hermosas y poéticas descripciones de sencillos cambios de la naturaleza que para él poseen un vigor excepcional en cuanto que le hacen experimentar una felicidad y un deseo de vivir en comunión con todo lo creado. La espera de la llegada de la primavera, con el leve descubrimiento diario de pequeñas transformaciones que observa en las plantas y los árboles que contempla desde su habitación, con la riqueza y diversidad de colores de las flores y los cielos que le hacen sobrecogerse y presentir una felicidad, es un acontecimiento que año tras año le hace escribir bellas páginas en su diario. En algunas de esas páginas, encontramos una profunda conmoción interior ligada a la inquietud y la excitación de un niño ante un juego que le emociona, hasta el punto de cambiar de una ventana a otra de su habitación con tal de no perderse nada de lo que ocurre en el exterior al comienzo de una primavera:

«La primavera se hace desear; el frío persiste, pero el jardín gana en brillo; el oro de los junquillos, el rojo de los tulipanes, cantan desde hace tres semanas; el frescor del aire les tiene en vilo.

Siempre, en este periodo del año, me siento feliz en lo más íntimo de mi ser; no quiero perderme nada del trabajo de las plantas y los árboles; acerco mi mesa contra la ventana alta repleta de las luces del norte. Después, llevo mis papeles al escritorio situado cerca de la ventana abierta que da al sur. Se

5 SpINK, K., Hermano Roger. La vida del fundador de Taizé, Barcelona, Herder, ${ }^{32009}$, p. 10.

6 Roger, F., Ta fête soit sans fin, Taizé, Les Presses de Taizé, 1971, p. 55. 
anuncia un aguacero; los primeros chirridos de las contraventanas sacudidas dejan presentir que una racha se acerca; está ahí y las gruesas gotas impactan contra las ventanas del sur. Me desplazo de nuevo hacia el lado norte. Ahí, todo es calma y serenidad. Una cortina de gasa, la lluvia impulsada por oleadas sucesivas asciende del sur» ${ }^{7}$.

Su interés por el tiempo, un interés habitual en las personas que han nacido en el campo, como él mismo reconoce, le hace ir rápidamente a la ventana nada más despertarse para mirar el cielo ${ }^{8}$. Los atardeceres le cautivaban y le hacían desear permanecer inmóvil contemplándolos indefinidamente: «Los atardeceres de cada estación me cautivan. Sobrecogido, me quedaría inmóvil indefinidamente. Mi sueño es tener una ventana que domine un vasto horizonte hacia el oeste ${ }^{9}$. Sus descripciones de los amaneceres y atardeceres poseen una gran fuerza expresiva, buscando los colores y las distintas luminosidades, el resplandor en el campo. Habituado a despertarse antes del alba durante el verano, observa los cambios de tonalidades y colorido del cielo nocturno dando paso al día:

«Las cuatro de la mañana. Salí un momento al rayar el alba, como casi todas las mañanas. El cielo, sembrado de estrellas, se vuelve blanco. Deja despuntar una aurora sin colorido. Hace un mes, a la misma hora, un cielo transparente, verde claro, en el norte y luego rápidamente incandescente. Ahora, brumas otoñales velan ya tanta fuerza luminosa ${ }^{10}$.

La sensibilidad del hermano Roger hacia la belleza de la naturaleza es extraordinaria y sus diarios testimonian una mirada contemplativa de excepción de la que carecen otras personas menos sensibles a la belleza:

«Una pesada lluvia ha caído durante toda la mañana. El jardín harto de agua deja estallar una sinfonía de colores. No me ha bastado ver la lluvia a través de los cristales. Cuando el trabajo me ha dejado un momento, he corrido bajo el sobradillo para escuchar el continuo caer del agua sobre el techo. Muy cerca de la casa, se ha abierto un paraguas y una voz ha echado pestes: "iQué asco de tiempo!». ¿Hasta qué punto puede el hombre pasar al lado de la belleza sin verla?» ${ }^{11}$.

En las descripciones que hace sobre la belleza de la naturaleza el hermano Roger emplea un lenguaje poético que reconocemos también en sus reflexiones espirituales. Su concepción de la creación como "poesía de la naturaleza» ${ }^{12}$ le influye en su manera de plasmar con palabras las escenas naturales que

7 Roger, F., Ta fête soit sans fin, Taizé, Les Presses de Taizé, 1971, p. 49-50.

8 Hermano Roger, Lucha y contemplación, Barcelona, Herder, ${ }^{2}$ 1976, p. 11.

9 Roger, F., Ta fête soit sans fin, Taizé, Les Presses de Taizé, 1971, p. 80.

10 Hermano Roger, Lucha y contemplación, Barcelona, Herder, ${ }^{2} 1976$, p. 26.

11 Hermano Roger, Vivir lo inesperado, Barcelona, Herder, ${ }^{2} 1985$, p. 25-26.

12 Roger, F., À la joie je t'invite. Fragments inédits, 1940-1963, Taizé, Ateliers et Presses de Taizé, 2012, p. 119. 
contempla y los sentimientos que surgen en ella. Él mismo afirma que «la creación poética es liberación»:

«Junto a mi ventana, dos palomas permanecen inmóviles sobre la pileta [...] Escribiendo, levanto los ojos para verlas, petrificadas en la espera de un aguacero que no cae. Falta tiempo para observar y me pongo a envidiar al poeta. Desde luego, de ninguna manera rechazo las enormes presiones de la existencia, que cada día entran en mi cuarto. Sin embargo, la creación poética es liberación» ${ }^{13}$.

No hay una narración de fenómenos naturales espectaculares sino más bien una atracción irresistible por el ritmo de la vegetación y la gratuidad de las flores ${ }^{14}$, una atención a las pequeñas cosas del día a día que pueden colmarle de una alegría serena:

«Encanto de todo lo que colma la mirada. Frescura de los cortos chaparrones. Al volver el sol, ellos avivan cada brizna de hierba. Felicidad de las primaveras de la infancia. Las contrariedades, las sombras, son lavadas por la lluvia fina, barridas por la cálida luz de un rayo de cobre. Y la carrera empieza otra vez, con la alternancia de saltos de alegría y de esperas defraudadas. En esas pequeñas cosas de nada se inscribe, como en filigrana, un amor a la vida, una fuente sin la cual todo sería insípido ${ }^{15}$.

Gracias a la mirada contemplativa del hermano Roger los acontecimientos más sencillos se convierten en oportunidades en las que descubrir la belleza de la creación: «Una mirada contemplativa nos arranca del entumecimiento de las ruinas y percibe tesoros de evangelio en los acontecimientos más sencillos. Descubre en el universo la radiante belleza de la creación ${ }^{16}$.

\subsection{Amar a Dios en su creación}

Los pasajes del diario del hermano Roger en los que se recogen referencias a momentos de contemplación de la naturaleza que le hacen sobrecogerse y descubrir una trascendencia tras ella, son frecuentes. Desde la ventana de su habitación que da al norte contempla cómo el viento empuja las nubes mientras los árboles permanecen quietos, y afirma: «Estoy ahí, abrumado por tanta felicidad, la mirada hacia lo alto ${ }^{17}$. Contemplar un paisaje en primavera le llena de alegría y le hace presentir una plenitud:

13 Hermano Roger, Lucha y contemplación, Barcelona, Herder, ${ }^{2} 1976$, p. 34.

14 Hermano Roger, Florecerán tus desiertos, Barcelona, Herder, 1984, p. 43.

15 Hermano Roger, Asombro de un amor, Barcelona, Herder, ${ }^{2} 1986$, p. 64.

16 Carta de Praga, 1991, p. 3. Las «Cartas de Taizé» son unas cartas que desde 1974, con motivo de la celebración del Concilio de Jóvenes, el hermano Roger redactaba cada año para preparar los temas de reflexión que se tratarían durante los encuentros semanales en Taizé. Tras su fallecimiento en 2005, el hermano Alois ha continuado redactando estas cartas.

17 Roger, F., Ta fête soit sans fin, Taizé, Les Presses de Taizé, 1971, p. 174. 
«No recuerdo haber vivido un inicio de mayo tan radiante. El aire cálido penetra la casa. Un viento desértico llega hasta nosotros. Puede que la primavera nunca haya llegado tan tarde. Además, esta alegría que estremece todo mi ser en cada renovación llega a su plenitud. [...] La alegría canta en mí. Mi atracción cada vez más profunda por los paisajes, y en particular por cada árbol, cada planta que adorna el jardín me llena de alegría» ${ }^{18}$.

Este sentimiento de felicidad se intensifica de manera especial en la contemplación de los atardeceres, momento en el que es consciente de que dicha felicidad le lleva directamente hacia $\operatorname{Dios}^{19}$. Por lo tanto, este disfrute de los distintos fenómenos naturales no es una experiencia estética cerrada en sí misma, sino que le remite a una trascendencia: «Los atardeceres de cada estación me cautivan. [...] Lleno de todo lo que la jornada ha ofrecido, podría quedarme solo, delante de este signo de infinito, sin notar esta soledad ${ }^{20}$. Alegría, asombro, fascinación, etc., son sentimientos que descubrimos en los textos en los que el hermano Roger describe los momentos de contacto con la naturaleza. Cuando descubre la "poesía» de la creación, percibe el «alba» de la vida eterna, una anticipación escatológica ${ }^{21}$. Sobrecogerse por la belleza de las cosas se convierte en una experiencia de contemplación:

«Cuando un ser humano comprende por intuición la gran belleza de las cosas, puede quedarse sobrecogido. ¿No es acaso la contemplación una disposición interior en la que la persona se encuentra completamente cautivada por el asombro de un amor, por la infinita belleza del Dios vivo? ${ }^{22}$.

Su mirada contemplativa le hace descubrir la belleza de la creación, tanto si se encuentra en un tiempo de oración como si lo hace en un momento de descanso tras la jornada simplemente observando el paisaje, una belleza que le remite a Dios:

«Sobre el promontorio de levante, domino el paisaje del bosque, hacia Chazelle. Está bien orar desde ahí, como también quedarse mirando las vacas, escuchar los cencerros, examinar un árbol, después otro.

Amar a Dios en su creación apacigua la pasión demasiado ardiente por los acontecimientos y los seres. Encontrar el ardor que anima cada estación, cada día de la estación, y, entonces, me encuentro incomparablemente dispuesto y alegre» ${ }^{23}$.

Amar a Dios en su creación o descubrir reflejos de eternidad en los dones de la creación, no le hace caer en el panteísmo, llega a explicitar que a través de la belleza de la creación acoge a Cristo:

18 Roger, F., À la joie je t'invite. Fragments inédits, 1940-1963, Taizé, Ateliers et Presses de Taizé, 2012, pp. 108-109.

19 Hermano Roger, Florecerán tus desiertos, Barcelona, Herder, 1984, p. 45.

20 Roger, F., Ta fête soit sans fin, Taizé, Les Presses de Taizé, 1971, p.80.

21 Hermano Roger, En ti la paz, Madrid, San Pablo, 1996, p. 38.

22 Idem., p. 51.

23 Roger, F., À la joie je t'invite. Fragments inédits, 1940-1963, Taizé, Ateliers et Presses de Taizé, 2012, p. 119. 
«Que canten en ti la alegría, el don radiante de la creación, ahí tus ojos disciernen reflejos de eternidad.

Tú, el Cristo, Salvador de toda vida, siempre vienes a nosotros.

Acogerte en la paz de las noches, en el silencio de los días, en la belleza de la creación, como en las horas de los grandes combates interiores, acogerte es saber que tú estarás con nosotros siempre» ${ }^{24}$.

\section{ARTE y BELLEZA}

\subsection{La creación artística como don de Dios}

El sentido de la belleza del hermano Roger se centraba, como hemos visto, en la naturaleza, aunque también era sensible a la belleza de la música y, en menor medida, a la belleza del resto de artes. Esto no significa que tuviese una valoración negativa del mundo del arte, al contrario, la creación artística estuvo presente en la Comunidad de Taizé prácticamente desde los inicios y la actividad de los talleres de arte tuvo cada vez más relevancia. Siempre trató de integrar esta vocación individual en el marco de la creación común a la que estaba llamada la Comunidad. De hecho, era tan consciente del valor que el artista otorgaba a su vocación que cuando una persona con dotes artísticos profundizaba en su vocación monástica no contraponía una con otra, sino que trataba de integrar ambas. Sin embargo, es cierto que las anotaciones en su diario sobre experiencias artísticas son escasas y suelen estar asociadas al universo musical. Él mismo era consciente de que su sentido de la belleza quizás se restringía en exceso a la naturaleza y olvidaba el arte:

«La visita de Don Alfons Roig me sumerge en un universo que tengo muy cerca pero que olvido, el mundo de los artistas. Hay ahí un no conformismo de actitudes, una admiración, un acento de alegría, una espera de nuevos descubrimientos. Debería recordarlo más a menudo. Restrinjo demasiado mi universo a la naturaleza inmediata, los árboles, el jardín, el cielo» ${ }^{25}$.

24 Roger, F., Les écrits fondateurs, Taizé, Ateliers et Presses de Taizé, 2011, p. 20

25 Roger, F., À la joie je t'invite. Fragments inédits, 1940-1963, Taizé, Ateliers et Presses de Taizé, 2012, p. 203. Alfons Roig Izquierdo (1903-1987), mantuvo una estrecha relación de amistad con algunos hermanos de la Comunidad de Taizé desde los años sesenta del siglo $\mathrm{XX}$ hasta su muerte. Fue un sacerdote valenciano muy interesado en cuestiones litúrgicas, artísticas y en la relación entre fe y cultura. Fue profesor de Arte y Arqueología Cristiana en el Seminario metropolitano de Valencia, donde influyó notablemente en sus alumnos por sus planteamientos modernos, fruto de su pasión por la literatura y el arte contemporáneos. Gracias a varias becas pudo viajar por Francia y Alemania Oriental para conocer de primera mano la arquitectura moderna. Mantuvo una relación de amistad con algunos intelectuales como María Zambrano o Eugenio d’Ors. En 1983, la Diputación de Valencia creó un premio y unas ayudas a las artes plásticas que llevan su nombre. Antes de morir, donó su biblioteca, su correspondencia y sus obras de arte a dicha Diputación; actualmente están depositadas en el Museo Valenciano de la Ilustración y la Modernidad (MuVIM). Para el perfil biográfico de Alfons Roig cf. Cárcel Ortiz, V., Obispos y sacerdotes valencianos de los siglos XIX y XX. Diccionario histórico, Valencia, Edicep, 2010, p. 754-756. 
Su escaso interés personal por el arte no le hizo insensible ni a la vocación de algunos de los hermanos ni al papel que desempeñaba la creación artística en la Comunidad, puesto que formaba parte de la creación común y era un medio más para manifestar la vocación ecuménica de paz y unidad a la que todos estaban llamados:

«Por lo tanto, día tras día podemos vehicular en esta colina, a través de nuestras personas, la paz, la serenidad y también los signos, signos de paz y de unidad. Estos signos se muestran en manifestaciones exteriores, como en, primero de todo, nuestro comportamiento, y también en el arte, los escritos, la expresión arquitectónica» ${ }^{26}$.

Cuando en los años setenta la acogida de jóvenes obliga a transformar las infraestructuras materiales de la colina y la Comunidad hace una reflexión sobre la eficacia de los medios, el hermano Roger recuerda que no se debe caer en el peligro de una rigidez que mira con recelo en qué se emplea el dinero, que quiere racionar todo, e indica que la creación artística es uno de los garantes de la dinámica de lo provisional que impide tender a la rigidez:

«En nombre de un radicalismo de Evangelio, a lo largo de la historia, los cristianos se han separado de toda creación, en particular de la artística. La creación artística puede ser uno de los test que nos ayudan a comprender si nosotros entramos en la rigidez en relación con el dinero o si conservamos una ligereza, dejándonos llevar por el soplo del Espíritu del mismo Dios» ${ }^{27}$.

Tampoco su insistencia en que la vida común estuviese marcada por el espíritu de pobreza y la sencillez hizo que rechazase el uso del arte en la iglesia, puesto que siempre rehuyó de la austeridad puritana de la tradición eclesial de sus orígenes. Más bien al contrario, el hermano Roger supo encontrar un camino en el que la belleza estuviese presente en la iglesia sin que esto implicase el uso de materiales lujosos que transmitiese una imagen de poder; una belleza basada en una simplificación que invita a «disponerlo todo en la belleza sencilla de la creación»:

«No se trata de rechazar el brillo de los esplendores artísticos de las iglesias construidas en la historia. Sin creación artística, se desarrollan corrientes de puritanismo y sectarismo, que deshumanizan presionando y provocando remordimientos de conciencia. Se trata más bien de disponerlo todo en la belleza simple de la creación; el mismo arte es un don de Dios. La sencillez de los medios no debe desembocar en una expresión opaca, donde lo insípido, lo convencional y lo monótono destilan aburrimiento ${ }^{28}$.

26 Archivo de la Comunidad de Taizé (en adelante, ACT), Conseil,1964, p. 1-2.

27 ACT, Conseil, 1977, «Conclusion de Notre Frère», p. 9.

28 Hermano Roger, Asombro de un amor, Barcelona, Herder, ${ }^{2} 1986$, p.107-108. 


\subsection{Levantar el velo de lo inefable}

Ya hemos visto que para el hermano Roger el arte es un don Dios y que la creación artística no debe verse mutilada por la mala conciencia que puede generar la austeridad severa del puritanismo. Su actitud frente a las artes no es de mera tolerancia, sino que las valora de manera positiva como un medio por el que se puede "presentir el misterio de Dios» y «levantar el velo de lo inefable»:

«Sin creación artística triunfarían las corrientes del puritanismo con su cortejo de mala conciencia. El mismo arte procede de Dios.

Hay manos de artistas que permiten descubrir rostros evangélicos, como el de Cristo o el de la Virgen María, hasta tal punto que una simple mirada ya hace presentir el misterio de Dios. Y en la música puede ocurrir que lo indecible nos conduzca a la oración y se levante el velo de lo inefable» ${ }^{29}$.

Los iconos, concebidos por el hermano Roger — siguiendo la teología ortodoxa- como "ventanas abiertas a las realidades de Dios» ${ }^{30}$, fueron empleados desde muy pronto por la Comunidad en la iglesia románica y, posteriormente, en la iglesia de la Reconciliación se ubicaron varios iconos, algunos antiguos, otros realizados por el hermano Eric y más recientemente, por otros artistas. En su habitación siempre había algunos iconos dispuestos sobre piedras o maderas, e iluminados por pequeñas velas. Entre ellos, uno era muy querido por el hermano Roger, el que recibió del Patriarca de Constantinopla Atenágoras durante una visita en 1970, y que le ayudaba a rezar, «no con muchas palabras, sino con el corazón ${ }^{31}$ :

«En la penumbra del atardecer, encima de mi chimenea, el icono de la Virgen. Una mariposa encendida dibuja los contornos de la Virgen con el Niño.

Desde la muerte de Atenágoras, este icono ha adquirido un nuevo relieve. Recuerdo al patriarca de Constantinopla insistiendo para que, con Max, eligiésemos para Taizé un icono en su catedral. Llenos de embarazo por este gesto, aceptamos el que estaba en peor estado, con la intención de hacerlo restaurar más tarde.

¡Un icono apenas iluminado! En la noche de cada cristiano, una luz ilumina los contornos de los seres y de las cosas, y la noche arde con un fuego que nunca se extingue» ${ }^{32}$.

La pasión que el hermano Roger sentía por la música se remonta a su infancia. Su madre cantaba y tocaba el piano, y Caroline Delachaux, hermana de su abuela, se lo enseñaba a sus siete hermanas, entre las que Geneviève era la más dotada, por lo que el hermano Roger vivió en un ambiente en el que la música estaba presente tanto a lo largo de la jornada, por la práctica de su madre y sus hermanas, como en las veladas nocturnas en las que sus padres tocaban y cantaban, y a las que el pequeño no asistía pero podía escuchar a través de la

29 Hermano Roger, Pasión de una espera, Barcelona, Herder, 1985, p. 156-157.

30 Hermano Roger, En ti la paz, Madrid, San Pablo, 1996, p.134.

31 Hermano Roger, Dios solo puede amar, Madrid, PPC, 2002, p. 99.

32 Hermano Roger, Vivir lo inesperado, Barcelona, Herder, ${ }^{2} 1985$, p. 44. 
puerta entreabierta de su habitación. En Provence, su tía también le enseñó las notas musicales y, posteriormente en Oron, aprendió algo de canto con un profesor de Lausana ${ }^{33}$. Ya en estos primeros años de vida, tenía predilección por la música barroca, especialmente por la obra de Bach, aunque también le entusiasmaban Chopin o Tchaikovski; algunos discos de este último compositor los escuchaba llorando de principio a fin ${ }^{34}$. Todos estos recuerdos de infancia asociados a la música y al canto denotan una gran sensibilidad y nos permiten comprender el valioso papel que les otorgaría tanto en su oración personal, durante los primeros años que estuvo viviendo solo en Taizé, puesto que, cuando tenía refugiados acogidos, se marchaba de la casa para rezar en el campo y poder cantar libremente, como en la oración común, una vez formada la Comunidad.

Pero el hermano Roger no solo valoraba la música y el canto como un medio privilegiado de alabanza en la oración, sino que también disfrutaba escuchando música en el tiempo de descanso. Las referencias a su autor favorito, Johan Sebastian Bach, son numerosas y suelen desprender una profunda emoción en su escucha: cuando una coral formada por jóvenes alemanes interpretan en la iglesia «O Jesu meine Freude» le «lleva al límite de la conmoción» ${ }^{35}$, cuando un hermano toca una fuga en el órgano de la iglesia y señala que, ante las preocupaciones y dificultades de la vida de Comunidad, «estos momentos son como un rocío refrescante» ${ }^{36}$, o cuando escucha varios días seguidos el «Concierto para oboe en re menor» y llega a hacer una descripción sinestésica de su experiencia:

«Según mi vieja costumbre de escuchar durante varios días seguidos las mismas piezas musicales, escribiendo pongo en el tocadiscos el concierto para oboe en re menor de Bach. En él percibo la imploración humana y una respuesta. Escucho en colores. Esta música es naranja, como lo es también el año que para mí acaba hoy» ${ }^{37}$.

Como vemos, el hermano Roger disfrutaba de la música y valoraba enormemente el goce estético que le producía. Este deleite no era meramente una distracción o un puro gozar estético, sino que en él encontraba un camino por el que alzar la súplica del ser humano a Dios, un medio con el que levantar el velo del Dios oculto: «En el arte de la música, puede ocurrir que lo indecible conduzca a la oración. Algunos conciertos de Johann Sebastian Bach hacen perceptible la súplica humana con una intensidad raramente alcanzada. Y se

33 ACT, Histoire de la famille. Documento de la Comunidad elaborado por el hermano Charles-Eugène, secretario personal del hermano Roger, que recoge los recuerdos de éste sobre su familia y su infancia así como testimonios de otras personas que reflejan los orígenes de Taizé.

${ }_{34}$ Spink, K., Hermano Roger. La vida del fundador de Taizé, Barcelona, Herder, ${ }^{32009}$, p. 35.

35 Roger, F., À la joie je t'invite. Fragments inédits, 1940-1963, Taizé, Ateliers et Presses de Taizé, 2012, p. 210.

36 Hermano Roger, Lucha y contemplación, Barcelona, Herder, ${ }^{2} 1976$, p. 62.

37 Roger, F., Ta fête soit sans fin, Taizé, Les Presses de Taizé, 1971, p. 173. 
levanta el velo sobre el Dios oculto de la Escritura» ${ }^{38}$. La música hace más accesible el misterio, la plenitud de Dios, como si a través de ella pudiésemos percibir algo de lo invisible: "Al volver de Florencia, me detengo en Romainmôtier para escuchar el nuevo órgano de la iglesia. [...] La plenitud que se halla en Dios se hace más accesible a través de la música. Como si los cielos se desgarrasen para hacernos oír algunas notas de lo invisible» ${ }^{39}$.

\section{LA BELLEZA DE LA ORACIÓN COMÚN}

\subsection{Belleza y liturgia}

Ante la pregunta «¿qué es lo más bello de su vida?», el hermano Roger respondía sin dudar: la oración común ${ }^{40}$, ya que, al ponerse delante de Dios junto con sus hermanos, consideraba que se realizaba lo esencial de su existencia ${ }^{41}$. Desde los orígenes de la Comunidad, la belleza del canto fue un elemento singular en la oración común y, posteriormente, a lo largo de los encuentros semanales de jóvenes que participaban en ella, el hermano Roger consideró que la belleza de la oración litúrgica era un gran apoyo de la vida interior y que podía provocar el deseo de Dios:

«Si para algunos la oración en soledad es ardua, la belleza de una oración cantada en común, incluso a dos o tres voces, es un apoyo incomparable de la vida interior. A través de palabras sencillas, cantos repetidos largamente, la oración puede irradiar una alegría. Una oración cantada conjuntamente ofrece dejar surgir en uno mismo el deseo de Dios y de entrar en una espera contemplativa. [...] Desde los primeros años de nuestra comunidad, con mis hermanos nos pusimos a cantar. Sabíamos leer algunos, a varias voces, corales de una intensa belleza... Entonces, he comprendido que el canto fue un apoyo irremplazable para la oración común» ${ }^{42}$.

Sin embargo, esa espera contemplativa de Dios en la oración no puede darse en celebraciones litúrgicas en las que las fórmulas estereotipadas, el exceso de palabras y de símbolos, provocan hastío y aburrimiento. Para que aquél que busca encontrarse con Dios en la oración litúrgica no quiera «huir», ésta debe ser acogedora y que en ella tenga cabida «la belleza del canto, la poesía, la adorable presencia del Resucitado...» $»^{43}$. Esta belleza del canto y de la oración no es una cuestión de esteticismo, sino que en ella brota una necesidad de comprender mejor a Dios, el propio Cristo se deja «percibir» y se puede intuir el

38 Hermano Roger, En ti la paz, Madrid, San Pablo, 1996, p. 74-75.

39 Hermano Roger, Vivir lo inesperado, Barcelona, Herder, ${ }^{2} 1985$, p. 51.

40 Hermano Roger, Dios solo puede amar, Madrid, PPC, 2002, p. 11.

41 Roger, F., À la joie je t'invite. Fragments inédits, 1940-1963, Taizé, Ateliers et Presses de Taizé, 2012, p. 202.

42 Roger, F., Pressens-tu un bonheur?, Taizé, Ateliers et Presses de Taizé, 2005, p. 91-92.

43 Roger, F., Les écrits fondateurs, Taizé, Ateliers et Presses de Taizé, 2011, p. 28. 
Misterio: «Cuando Cristo Jesús se deja intuir en la belleza de la oración común, una sed de comprender toma vida. Lo que más importa en un principio no son los grandes conocimientos. Ellos tienen mucho valor, pero será la intuición la primera en penetrar el Misterio de la Fe» ${ }^{44}$.

El hermano Roger fue muy consciente de que la oración litúrgica de la Comunidad debía ser accesible a todas las personas, jóvenes o ancianas, que se acercaban a Taizé. La oración común es el símbolo mediante el que la unidad de los cristianos se hace visible. La belleza del canto y de la sencillez de los símbolos de la oración común es un medio privilegiado que puede conducir a la comunión con Dios:

«Nada lleva más a la comunión con Dios vivo que una amplia oración común, meditativa y accesible a todas las edades. Y dentro de ella esta cumbre de la oración que es el canto que no acaba nunca y que continúa luego en el silencio del corazón, cuando nos encontramos a solas. [...] Cuando el misterio de Dios se hace perceptible a través de la simple belleza de los símbolos, cuando no está sofocada por una sobrecarga de palabras, entonces una amplia oración común, lejos de destilar monotonía o aburrimiento, da paso a la alegría de Dios sobre la tierra de los hombres» ${ }^{45}$.

Como vemos, para el hermano Roger en la belleza de la oración se revela el misterio de Dios y se desvela algo de lo inefable, dando lugar a una alegría del cielo en la tierra que lejos de alejar al orante de la realidad y de sus conflictos, le empuja a tomar compromisos para hacer la tierra más habitable:

«En la belleza de una oración común se desvela algo de lo inefable de la fe y lo indecible lleva a la adoración. La mirada mística descubre un reflejo de la alegría del cielo en la tierra e intuye cómo franquear las rupturas de la comunión para ponerse en camino hacia las reconciliaciones» ${ }^{46}$.

\subsection{Liturgia y provisionalidad}

La oración común de la Comunidad de Taizé nació como un Oficio de una comunidad monástica, con la particularidad de que sus miembros procedían de distintas confesiones protestantes y, por lo tanto, sin una tradición litúrgica que seguir, lo que conllevó una mayor libertad a la hora de configurar la liturgia de una oración común que quería ser un signo de la unidad de la Iglesia. Debido a la mayor afluencia de jóvenes que querían compartir por unos días la vida de la Comunidad, el Oficio fue transformándose en una oración común más simplificada que permitiese una participación activa de todos los asistentes, muchos de los cuales no compartían ni la procedencia eclesial ni la lengua.

En el Consejo de Comunidad de enero de 1974, el año en que iba a celebrarse la apertura del Concilio de los Jóvenes, el hermano Roger exhortaba a los

44 Hermano Roger, Amor de todo amor. Las fuentes de Taizé, Madrid, PPC, ${ }^{2} 1995$, p. 44.

45 Hermano Roger, Pasión de una espera, Barcelona, Herder, 1985, p. 114-115.

46 Hermano Roger, Carta de Praga, 1991, p. 3. 
hermanos a disipar toda duda que tuviesen en relación con los cambios que se estaban produciendo en la oración común con el fin de hacerla más accesible a todos los jóvenes que acudían en miles a Taizé con vistas a la celebración del Concilio. Según él, las formas que adopta la oración son diversas tanto en la historia de la Iglesia como en la vida de cada persona, pero siempre se debe mantener esa marcha del hombre hacia Dios, mientras que la oración común no eliminase el sentido del misterio:

«El fondo de la oración común es este camino inmutable del hombre hacia Dios, del hombre que tiene sed de una presencia. Pero la expresión de este itinerario es múltiple, se diversifica según los pueblos, los periodos de la historia, los periodos de nuestra vida. Esta adaptación en la expresión de la oración no es evidente. Todo es posible cuando uno ora solo, incluso el hablar en lenguas, pero desde el momento en que estamos con otros, se imponen unos límites, sobre todo cuando un gran número de gente viene a unirse a nuestra oración. Esta voluntad de ayudar al mayor número posible de personas a entrar en este camino del hombre hacia Dios, no nos autorizará jamás a eliminar ni un pedazo de la roca de la fe, el misterio pascual. Si alguien tiene alguna inquietud a este respecto, es fundamental que se disipe ${ }^{47}$.

Lo que permanece inmutable en la oración es la sed de Dios que tiene el ser humano, mientras que su expresión está sujeta a una transformación, es decir, es provisional. En este caso, la modificación de la oración litúrgica viene determinada por la participación activa de los jóvenes, en plena coherencia con los principios derivados de la reforma litúrgica impulsada por la Iglesia Católica en el Concilio Vaticano II. Por lo tanto, la provisionalidad no se debe a una falta de respeto por la tradición ni por un gusto del cambio por el cambio, por la mera novedad, sino que las transformaciones que se producen en el seno de la oración común de la Comunidad tienen una finalidad pastoral clara: acompañar a los jóvenes en su itinerario hacia Dios.

Sin embargo, no solo la afluencia de jóvenes determinó el cambio en la forma de la oración litúrgica de la Comunidad sino que ya desde los orígenes encontramos algunas reflexiones del hermano Roger en las que advierte del peligro del formalismo como uno de los peligros que acechan a la vida espiritual: «Uno de los peligros que te amenazan, si aceptas una disciplina espiritual, es el del formalismo y la rutina; sucumbes a ellos cada vez que tu disciplina espiritual no brota de la fe, cada vez que ella no se mueve por amor a Cristo ${ }^{48}$. En particular, la liturgia era uno de los ámbitos espirituales en los que el formalismo podía convertirse en un peso que frenase la marcha de la Comunidad. A pesar de ello, el hermano Roger reconocía el valor que podía tener la repetición de formas litúrgicas estereotipadas que no habían cambiado a lo largo de los siglos, pero de igual manera, esperaba que se reconociese que podían existir otras expresiones que también poseían el poder de la comunicación:

47 ACT, Conseil, 1974, «La prière commune», p. 11.

48 Schutz, R., Introduction à la vie communautaire, Ginebra, Labor et Fides, 1944, p. 81. 
«Por ejemplo, muchos quedan conquistados y experimentan la continuidad de Dios en la Iglesia a través de la repetición de gestos, de himnos, de formulaciones invariables. Estos lugares privilegiados son, para muchos, irremplazables tierras de Iglesia. Pero hay otras expresiones por las que Dios conquista al hombre ${ }^{49}$.

Él mismo se preguntaba cómo una oración basada en la repetición cíclica de los mismos textos no acababa conduciendo indefectiblemente al automatismo. En su propia experiencia reconocía que había periodos de alternancia entre el descubrimiento de la liturgia como un auténtico tesoro de la Iglesia, en cuyos textos encontraba un soplo siempre nuevo, y los días en los que el frescor de los textos se cubría de un sutil polvo y la fatiga se apoderaba de la repetición incesable de las oraciones y los himnos. Cuando la oración común le suponía un peso en su marcha, se confiaba a la oración espontánea como medio de liberación, pero el peligro del conformismo se encontraba tanto en la repetición de fórmulas estereotipadas como en la imposición de las formas personales de expresión. De modo que, volviendo a los textos tradicionales lo único que le importaba era la constancia en la fidelidad y la renovación del hombre interior ${ }^{50}$. En cualquier caso, el hermano Roger no otorgaba un valor absoluto a ninguna expresión litúrgica y, habiendo experimentado tanto una oración basada en la espontaneidad como otra más formalista, el fervor o la indiferencia podían darse en cualquiera de ellas:

«Son numerosos los cristianos que pretenden poseer la verdadera expresión de la oración. Unos están seguros de que su oración no es auténtica si no surge espontáneamente de su corazón. Tratan de formalistas a aquellos que oran siguiendo las antiguas oraciones del Pueblo de Dios. Habiendo practicado tanto una como otra, constato que mi indiferencia o mi fervor se encuentran cómodos en una y en otra forma» ${ }^{51}$.

En un artículo que trataba sobre la oración de la Comunidad de Taizé, publicado en 1956 en la revista Foi et Vie $e^{52}$, el hermano Roger señalaba que la oración litúrgica y la oración espontánea son dos elementos indispensables y complementarios en el culto regular de una comunidad. Por un lado, la oración espontánea garantiza que la intercesión y la alabanza se alimenten de la actualidad del momento presente, pero recurrir exclusivamente a la espontaneidad pone en riesgo la oración al limitarla al aquí y ahora. Por otro lado, una comunidad comprometida con la oración litúrgica debe vencer el peligro que puede suponer el conformismo, es decir, tratar de no habituarse a que determinadas

49 Schutz, R., La regla de Taizé. Unanimidad en el pluralismo, Barcelona, Herder, 1968, p. 92 .

50 Roger, F., À la joie je t'invite. Fragments inédits, 1940-1963, Taizé, Ateliers et Presses de Taizé, 2012, p. 50-51.

51 Idem. p. 80.

52 Schutz, R., «Notes sur la prière dans la communauté de Taizé», en: Foi et Vie, nº 1 (enero-febrero 1956), pp. 69-73. Algunos extractos pueden consultarse en RoGER, F., À la joie je t'invite. Fragments inédits, 1940-1963, Taizé, Ateliers et Presses de Taizé, 2012, p. 111-116. 
fórmulas se vacíen y pierdan su sentido. Así, el hermano Roger recordaba que el descubrimiento de la oración de la Iglesia indivisa de los primeros siglos no obliga a asumirla sin ejercer ningún tipo de crítica, sino que la renovación litúrgica, lejos de convertirse en una búsqueda arqueológica, debe ser accesible al hombre de hoy y, por esa razón, una de las constantes preocupaciones de la Comunidad es revisar el vocabulario y la sintaxis de ciertos textos para hacerlos accesibles al hombre de hoy en día.

Como vemos, para el hermano Roger, la oración puede adoptar distintas expresiones, pero existe un sustrato que permanece inmutable: en la marcha del ser humano hacia Dios, descubre que «ha sido creado para ser habitado por Otro distinto de él $»^{53}$. Una oración que siempre es pobre, ya que el ser humano percibe un exceso de sentido, «hay como un más allá de lo que somos, un más allá de nuestras propias palabras ${ }^{54}$. Manteniéndose estable este fondo de la oración, su expresión cambia según el momento histórico y la vida de cada persona: unos oran en un gran silencio mientras que otros lo hacen con muchas palabras, unos encuentran en la liturgia «la alegría del cielo en la tierra» mientras que otros repiten hasta el infinito algunas palabras; y algunos nunca experimentan la «resonancia sensible de una presencia en ellos» ${ }^{55}$. Sea cual sea la expresión de la oración, lo que es esencial en ella es la apertura del ser humano a la vida que viene de Otro:

«Los caminos de la oración son muchos. Algunos siguen sólo unos, otros los recorren todos. Hay momentos en que la certeza es viva: Cristo está aquí, habla dentro de nosotros. Pero hay otros momentos en que es el Silencioso, un lejano Desconocido... No existen privilegiados de la oración. Diversa hasta el infinito, la oración es para todos un paso a una vida que no viene de nosotros mismos, sino de fuera ${ }^{56}$.

La propia forma de la oración litúrgica de la Comunidad es provisional no solo como lo demuestra la evolución que ha sufrido a lo largo de su historia sino también en el sentido de signo visible y anticipación de la unidad de la Iglesia, puesto que en ese momento se podría determinar una liturgia común a todas las tradiciones eclesiales. Mientras se logra la unidad, la oración común de la Comunidad ecuménica de Taizé es un testimonio de indignación y una expresión simbólica de violencia frente a las separaciones confesionales ${ }^{57}$. En ningún caso, la Comunidad quiere que su oración se constituya en una corriente de liturgia, sino que, simplemente, sea una realidad visible que muestre su camino de unidad $^{58}$.

53 Hermano Roger, Vivir lo inesperado, Barcelona, Herder, ${ }^{2} 1985$, p. 33.

54 Idem., p. 34.

55 Idem., p. 34-35.

56 Idem., p. 36.

57 Schutz, R., La violencia de los pacíficos, Barcelona, Herder, ${ }^{3} 1978$, p. 159.

58 Schutz, R., La regla de Taizé. Unanimidad en el pluralismo, Barcelona, Herder, 1968, p. 88 . 


\subsection{El sentido del misterio}

Para el hermano Roger, la oración litúrgica es un signo de la unidad de la Iglesia, es la realidad visible que manifiesta el combate por la unidad y que se encuentra en el corazón de la vida comunitaria. La oración común de la Comunidad de Taizé bebe de las fuentes de la fe, de las distintas tradiciones eclesiales, de modo que se configura como un «mosaico» en el que, sin inventar nada, se ha adaptado la oración de todos los siglos ${ }^{59}$. De las confesiones protestantes destaca la relevancia otorgada a la meditación de la Escritura; el valor de la adoración derivado de la presencia de Cristo en la Eucaristía es propia de la tradición católica; y, la liturgia que hace perceptible el Espíritu del Resucitado es característico de las iglesias ortodoxas ${ }^{60}$.

El hermano Roger, que valoraba profundamente el canto en la oración común, reconoce la influencia que la himnología de la tradición protestante había tenido en la forja de la oración de la Comunidad, puesto que la consideraba «el tesoro más preciado que ha dejado la Reforma para edificar nuestra piedad $»^{61}$. De igual modo, en la tradición ortodoxa también encuentra una fuente de inspiración para el canto, como muestran las numerosas referencias de sus diarios, debido a su belleza y a su fuerza expresiva, que le hacen concebirla como «una visitación de Dios, la alegría del Espíritu Santo visible entre los seres humanos $»^{62}$.

La oración de la Comunidad de Taizé, sin caer en el sincretismo, ha sabido recuperar los elementos litúrgicos más valiosos de cada tradición de modo que la propia liturgia se convierte en un signo de unidad. Sin embargo, la Comunidad no ha pretendido constituirse en un modelo o una corriente litúrgica a seguir, ni tampoco considera que su oración representa la quintaesencia de la liturgia; de hecho, el hermano Roger considera que la oración litúrgica, aun siendo aquello que particulariza a la Comunidad, deberá desaparecer el día que se realice la unidad visible ${ }^{63}$, y, en su forma histórica, no ha dejado de evolucionar desde los orígenes de la Comunidad:

«En nuestros comienzos, elaboramos, sobre todo, una oración monástica. Luego, para llegar mejor al pueblo de Dios, procuramos hacerla, al mismo tiempo, meditativa y popular, accesible a todas las generaciones y lo más universal posible. Que deje presentir la espera del reino de Dios y el corazón universal de la Iglesia.... ${ }^{64}$.

59 Schutz, R., La violencia de los pacíficos, Barcelona, Herder, ${ }^{3} 1978$, p. 44.

60 Hermano Roger, Florecerán tus desiertos, Barcelona, Herder, 1984, p. 97.

61 Roger, F., À la joie je t’invite. Fragments inédits, 1940-1963, Taizé, Ateliers et Presses de Taizé, 2012, p. 147.

62 Roger, F., Pressens-tu un bonheur?, Taizé, Ateliers et Presses de Taizé, 2005, p. 131.

${ }^{63}$ Schutz, R., La regla de Taizé. Unanimidad en el pluralismo, Barcelona, Herder, 1968, p. 107.

${ }^{64}$ Hermano Roger, Florecerán tus desiertos, Barcelona, Herder, 1984, p. 109. 
Para el hermano Roger, las Iglesias orientales insisten más en los valores místicos mientras que en Occidente se acentúa más la teología especulativa. Por esta razón, la liturgia oriental puede ayudar a la contemplación del misterio ya que «hace trasparecer algo de lo invisible, de este invisible al que aspiran, más o menos los creyentes y los que no creen ${ }^{65}$. En la visita que realizó al Monte Athos en junio de 1963, con motivo de las celebraciones de su milenario, afirmaba que la liturgia se había convertido en un medio de unidad entre la iglesia ortodoxa griega y los patriarcas de las iglesias de los países del Este. Asimismo, señalaba que habían sido unos días en los que «la alegría del cielo resplandece sobre la tierra de los hombres, incluso si no podemos comprenderlo mediante la inteligencia ${ }^{66}$. En numerosas ocasiones, el hermano Roger manifestó el gran amor que sentía hacia la Iglesia ortodoxa, un amor que se deja entrever en la influencia que el sentido del misterio, manifestado a través de la belleza del canto, el uso de los iconos y de los símbolos de su liturgia, tiene en la oración de la Comunidad:

«En Taizé, amamos a la Iglesia ortodoxa con todo nuestro corazón, con toda el alma. En sus lugares de oración, la belleza de los cantos, el incienso, los iconos —esas ventanas abiertas a las realidades de Dios-, los símbolos y los gestos de la liturgia celebrada en la comunión de los cristianos desde hace siglos, todo llama a discernir la «alegría del cielo sobre la tierra». El ser en su globalidad es tocado, no solamente en su inteligencia, sino también en su sensibilidad, y hasta en el propio cuerpo ${ }^{67}$.

Como vemos, para el hermano Roger, el sentido de misterio que envuelve toda la liturgia ortodoxa se realiza a través de una valoración de los sentidos corporales (cantos, iconos, velas, incienso, etc.), y él mismo, en su propia oración, daba mucha importancia al papel activo que debían jugar los sentidos en ella, frente a la oración comunitaria de tradición protestante, centrada en la palabra y orientada estrictamente a lo intelectual:

«Nuestra espiritualidad protestante gira en torno a los discursos, la palabra, de ahí su constante llamada a la inteligencia. Ella se ha debilitado a causa de su autodefensa.

Solo una vuelta a las fuentes de la Iglesia Universal (tanto de Oriente como de Occidente) permitirá abandonar los discursos para que nos penetre la luz de Cristo; no tanto hablar sino mirar, contemplar, escuchar ${ }^{68}$.

Para él, la oración no podía convertirse en «un discurso cerebral, secularizado hasta el punto de eliminar el sentido del misterio, de la poesía, sin dejar

65 Hermano Roger, Dinámica de lo provisional, Monserrat, Editorial Estela, ${ }^{2} 1967$, p. 48.

66 Roger, F., À la joie je t'invite. Fragments inédits, 1940-1963, Taizé, Ateliers et Presses de Taizé, 2012, p. 196.

67 Roger, F., Pressens-tu un bonheur?, Taizé, Ateliers et Presses de Taizé, 2005, p. 133-134.

68 Roger, F., À la joie je t'invite. Fragments inédits, 1940-1963, Taizé, Ateliers et Presses de Taizé, 2012, p. 124. 
lugar a la oración del cuerpo, la intuición y la afectividad» ${ }^{69}$. Así, el cuerpo y los sentidos cobran una especial relevancia en la oración, frente a una visión negativa del cuerpo, como obstáculo para el itinerario espiritual:

«En cuanto a mí, no sabría cómo orar sin el cuerpo. No soy un ángel y no lo lamento. En ciertos periodos, he tenido conciencia de orar más con el cuerpo que con la inteligencia. Una oración a ras de suelo: doblar las rodillas, postrarse, mirar el lugar donde se celebrará la eucaristía, hacer uso del silencio apaciguador e incluso de los ruidos que vienen del pueblo. El cuerpo está ahí, bien presente, para escuchar, comprender, amar. ¡Qué ridiculez no querer contar con él!» ${ }^{70}$.

Incluso en los momentos de aridez en la oración en los que parece que no podemos expresar nada con palabras, «la oración del cuerpo toma el relevo para indicar una intención o para abandonarse al silencio de Dios [...] Es todo un lenguaje el que podemos tener para con Dios, a través del gesto, la intención, eso que emana de nosotros mismos ${ }^{71}$. Incluso uno de los símbolos litúrgicos más representativos de la experiencia de una semana que viven los jóvenes en Taizé, como es el de la oración de la cruz que se realiza cada viernes al final de la oración de la noche, es un símbolo traído de un viaje a Moscú en junio 1978 en el que la oración se realiza con todo el cuerpo:

«Hemos traído un nuevo símbolo de Moscú: los viernes por la noche, colocar el icono de la cruz en el suelo y apoyar la frente sobre la madera de la cruz, depositando en Dios - mediante una oración de todo el cuerpo-, las propias dificultades y las de los demás. Y, acompañar así al Resucitado, que continúa estando en agonía por aquellos que sufren a través de la tierra» ${ }^{72}$.

Y, sin embargo, el hermano Roger sabía muy bien que la experiencia de Dios no podía ni someterse a una técnica construida por el ser humano, con el peligro de "alcanzar un Dios fabricado por las proyecciones humanas» ${ }^{73}$, ni contener el misterio de Dios en determinados signos litúrgicos, que nos lo hacen más accesible pero que no lo agotan al ser de otro orden, de modo que, contando con ellos, deben ser signos sencillos:

«Estemos atentos para penetrar el sentido de la acción litúrgica. Busquemos el discernir, bajo los signos accesibles a nuestro ser de carne, una realidad invisible de orden del Reino. Pero velemos también por no multiplicar estos signos, y guardar su simplicidad, prenda de su valor evangélico» ${ }^{74}$.

\footnotetext{
69 Roger, F., Ta fête soit sans fin, Taizé, Les Presses de Taizé, 1971, p. 9.

70 Idem., p. 49.

${ }^{71}$ Hermano Roger, Asombro de un amor, Barcelona, Herder, ${ }^{2} 1986$, p. 78.

72 Hermano Roger, Florecerán tus desiertos, Barcelona, Herder, 1984, p. 128.

73 Hermano Roger, Pasión de una espera, Barcelona, Herder, 1985, pp. 48-49.

74 Schutz, R., La regla de Taizé. Unanimidad en el pluralismo, Barcelona, Herder, 1968, p. 19.
} 
El canto es uno de esos signos litúrgicos que permiten tanto abrirse a «la alegría del cielo descendida sobre la tierra ${ }^{75}$, como liberar aquello que interiormente bloquea la oración:

«El canto de un coral o de un salmo puede ser el arma poderosa que permite recuperarse. Cuando surge con fuerza, sale de sí mismo, libera los obstáculos, las angustias. Te prepara para dirigir a Dios tu búsqueda, tu alabanza, tu adoración, espontáneamente, según tus expresiones familiares» ${ }^{76}$.

\subsection{Esperar el acontecimiento de Dios}

Como hemos visto, para el hermano Roger la oración se sitúa en el centro de la vida de la Comunidad puesto que es el signo más auténtico mediante el que se realiza su compromiso con la unidad de la Iglesia ${ }^{77}$, pero, sobre todo, porque en ella se produce una comunicación con Dios, un diálogo no consigo mismo sino en sí mismo ${ }^{78}$, que se fundamenta en mantenerse delante de Él, tanto si se hace en la certeza de su presencia como si ésta no es sensible de ninguna manera: «El mantenernos ante Dios no supera nuestra medida humana. La presencia objetiva de Dios no está ligada a la sensibilidad. Está allí en los momentos en que el fervor se disipa y en los que se desvanece en nosotros la resonancia sensible de Cristo ${ }^{79}$. Para el hermano Roger, orar es permanecer en la espera contemplativa de Dios, la espera del acontecimiento de Dios:

«Cuantas veces, cuando estamos reunidos para la oración común, en la iglesia, me sobrecoge el asombro. Estos hombres, hermanos míos, compañeros de mi vida, permanecen fieles en la espera de Dios. Están ante Dios sin ver, en cierto sentido, sin saber cuál será la respuesta a su espera. [...] ¡Qué cierto es que estamos durante toda nuestra vida de cristianos, en el tiempo de la espera! Desde Abraham, el primer creyente, y con toda su estirpe, estamos en la espera de Dios, de su justicia, del acontecimiento que viene de Él» ${ }^{80}$.

La oración es una espera en la que el ser humano puede descubrir que está habitado por Otro distinto de él ${ }^{81}$; una espera en la que se actualiza el «iVen Señor!» del Apocalipsis, una espera que no es huida ni proyección de uno mismo puesto que llega un momento en el que se puede afirmar: «tú eres el Otro,

75 Roger, F., À la joie je t'invite. Fragments inédits, 1940-1963, Taizé, Ateliers et Presses de Taizé, 2012, p. 25.

76 Schutz, R., Introduction à la vie communautaire, Ginebra, Labor et Fides, 1944, p. 82.

77 Schutz, R., La regla de Taizé. Unanimidad en el pluralismo, Barcelona, Herder, 1968, p. 88 .

7 Schutz, R., La violencia de los pacíficos, Barcelona, Herder, ${ }^{3} 1978$, p. 38.

79 Schutz, R., La regla de Taizé. Unanimidad en el pluralismo, Barcelona, Herder, 1968, p. 115.

80 Hermano Roger, Dinámica de lo provisional, Monserrat, Editorial Estela, ${ }^{2} 1967$, pp. $71-72$

${ }^{81}$ Hermano Roger, Vivir lo inesperado, Barcelona, Herder, ${ }^{2} 1985$, p. 33. 
aquel que existe en sí mismo» ${ }^{82}$. En la medida en que la oración deja presentir la «espera del Reino» ${ }^{83}$ es un acto de carácter escatológico en el que nos vemos arrancados del tiempo, en el que se pone entre paréntesis toda nuestra existencia: «Por otra parte, ¿no es la oración común un lugar en el que el tiempo se califica de otro modo, en donde adquiere un peso de eternidad? Por la oración de la Iglesia todos juntos quedan provisionalmente arrancados al tiempo ${ }^{84}$.

Para el hermano Roger, la oración litúrgica es un signo de lo intemporal en el que se deja presentir al hombre el acontecimiento de Dios y donde su trascendencia se haga más sensible ${ }^{85}$. Frente a las formulaciones estereotipadas, el automatismo y la ausencia de participación, es indispensable que la oración litúrgica mantenga el sentido de lo sagrado, el misterio, pero que lo haga a través de «actos, gestos, signos humildes que alcancen las profundidades de nosotros mismos» ${ }^{86}$. De ahí la importancia de la belleza de la oración común, puesto que a través de la belleza del canto y de la belleza sencilla de los símbolos, se hace perceptible el misterio de Dios:

«Nada conduce tanto a la comunión con el Dios vivo como una oración común meditativa, con esa cumbre de la oración: el canto que se prolonga y que continúa en el silencio del corazón cuando estamos solos. Cuando el misterio de Dios se hace perceptible en la belleza sencilla de los símbolos, cuando no está ahogada bajo una sobrecarga de palabras, entonces la oración común, lejos de destilar la monotonía y el aburrimiento, abre a la alegría del cielo en la tierra ${ }^{87}$.

Así, la oración común de la Comunidad de Taizé acoge el sentido del misterio y de la belleza y puede hacer más accesible la experiencia de Dios, puesto que ayuda a mantenerse en la espera contemplativa de Dios, tanto si la oración deja presentir su misterio, como si no existe ninguna resonancia sensible.

Universitat Ramon Llull

Salvador García Arnillas

Facultat de Comunicació i Relacions Internacionals Blanquerna

salvadorga@blanquerna.url.edu

[Artículo aprobado para publicar en enero de 2019]

82 Roger, F., Ta fête soit sans fin, Taizé, Les Presses de Taizé, 1971, pp. 69-70.

83 Hermano Roger, Florecerán tus desiertos, Barcelona, Herder, 1984, p. 109.

84 Schutz, R., La violencia de los pacíficos, Barcelona, Herder, ${ }^{3} 1978$, p. 40.

85 Schutz, R., La regla de Taizé. Unanimidad en el pluralismo, Barcelona, Herder, 1968, p. 87 .

86 Hermano Roger, Dinámica de lo provisional, Monserrat, Editorial Estela, ${ }^{21967, ~ p . ~} 15$

87 Carta "Alegría inesperada», 1998, p. 6. 